ISSN: 0213-2060

DOI: https://doi.org/10.14201/shhme2017351157178

\title{
USURPACIONES DE TIERRAS COMUNALES EN EL TÉRMINO DE PLASENCIA A FINES DE LA EDAD MEDIA
}

\author{
Land Communal Usurpations in the City Municipal Area of Plasencia \\ at the End of Middle Ages
}

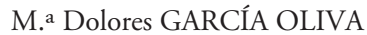

Depto. de Historia. Facultad de Filosofía y Letras. Universidad de Extremadura. Avda. de la Universidad, s/n. E-10071 CÁCERES. C. e.: gciaoliv@unex.es

Recibido: 2016-05-06

Revisado: 2017-01-07

Aceptado: 2017-05-09

RESUMEN: En este trabajo se analizan las usurpaciones de tierras en el término placentino denunciadas a finales del siglo XV y principios del siglo XVI. En ellas participaron todos los señores y las villas situadas en el término, pero también caballeros placentinos, y afectaron fundamentalmente al Campo Arañuelo y a la zona comprendida entre los ríos Tajo y Almonte, los espacios de menor densidad demográfica. La iniciativa contra estos abusos fue tomada a veces por el concejo de la ciudad, pero las aldeas de realengo también tuvieron un papel destacado en la defensa de los comunales.

Palabras clave: Baja Edad Media; Extremadura; Concejos; Oligarquía; Usurpación de comunales.

ABSTRACT: This essay analyses the land usurpations into the municipal area of Plasencia (Cáceres) reported at the end of $15^{\text {th }}$ Century and beginning of $16^{\text {th }}$ Century. In these usurpations took part the practically totality of the members of the neighbouring nobility, the local knights and the villages located inside the municipal area. The usurpations mainly affected to Campo Arańuelo and the area comprised between the rivers Tagus and Almonte; i. e., the spaces with less demographic density. The main initiative against these abuses was sometimes taken by the city council, but also the royal small villages had an outstanding role at the defence of communal goods. 
USURPACIONES DE TIERRAS COMUNALES EN EL TÉRMINO DE PLASENCIA

A FINES DE LA EDAD MEDIA

M. ${ }^{\mathrm{a}}$ DOLORES GARCÍA OLIVA

Keywords: Late Middle Age; Extremadura; City councils; Oligarchies; Communal usurpations.

SUMARIO: 0 Consideraciones previas. 1 Las reclamaciones de tierras comunales por parte del concejo durante el señorío de don Álvaro de Zúñiga. 2 Las reivindicaciones de tierras usurpadas a partir del regreso de la ciudad a la jurisdicción realenga. 3 Referencias bibliográficas.

\section{CONSIDERACIONES PREVIAS}

Las denuncias por apropiaciones de tierras comienzan a aparecer en la documentación extremeña ya en las últimas décadas del siglo xiII, pero, salvo algunas excepciones, no alcanzaron relevancia hasta mediados del siglo XIV y, sobre todo, en el Xv, especialmente en el reinado de Juan II, a partir de los ańos treinta, y durante el reinado de los Reyes Católicos, algo que también sucedió en otras zonas del reino castellano ${ }^{1}$.

1 Las noticias sobre usurpaciones de tierras se remontan a las últimas décadas del siglo XIII en Badajoz (Rodríguez Amaya, Esteban. «La tierra en Badajoz desde 1230 a 1500». Revista de Estudios Extremeños, 1951, vol. VII, p. 407), Plasencia y Trujillo (García Oliva, M. ${ }^{a}$ Dolores. Poblamiento y expansión de las dehesas en el realengo de Extremadura, siglos XII-XV. Cáceres: Universidad de Extremadura, 2015, p. 179). Pocos ańos después, en la minoría de Alfonso XI, se documentan abusos de esa índole en Córdoba (CABRERA Muñoz, Emilio. «Usurpaciones de tierras y abusos señoriales en la Sierra cordobesa durante los siglos XIvXV». Actas del I Congreso de Historia de Andalucía. Andalucía Medieval. Córdoba: Monte de Piedad y Caja de Ahorros de Córdoba, 1978, vol. II, p. 37); y, cuando ese rey llegó a la mayoría de edad, el problema debía estar bastante extendido en el reino dado que, según destacó M. ${ }^{a}$ Antonia Carmona, en las Cortes de Madrid de 1329 los procuradores de las ciudades denunciaron que habían sido usurpadas muchas tierras comunales (Carmona Ruiz, M. ${ }^{a}$ Antonia. Usurpaciones de tierras y derechos comunales en Sevilla y su «tierra» durante el siglo XV. Madrid: Ministerio de Agricultura, Alimentación y Medio Ambiente, 1995, pp. 85-86). Un año más tarde, en 1330, el proceso está documentado en Ávila (Monsalvo AnTón, José M. ${ }^{a}$ « «Usurpaciones de comunales: conflicto social y disputa legal en Ávila y su Tierra durante la Baja Edad Media». Historia Agraria, 2001, vol. 24, p. 90). Hacia mediados del siglo xiv se detecta un aumento de las denuncias por este problema, aumento más notable en el siglo Xv según se ha puesto de manifiesto en varios trabajos. Entre ellos podemos citar, además de los ya indicados, los de Martín MarTín, José Luis. «Evolución de los bienes comunales en el siglo Xv». Studia Historica. Historia Medieval, 1990, vol. 8, pp. 17 y ss.; Jara Fuente, José Antonio. «Que memoria de onbre non es en contrario. Usurpación de tierras y manipulación del pasado en la Castilla urbana del siglo XV». Studia Historica. Historia Medieval, 2002-2003, vol. 20-21, p. 76; Lorenzo Pinar, Francisco Javier e Izquierdo Misiego, José Ignacio. «Términos redondos y despoblamiento en Ávila al inicio de la Edad Moderna. Aproximación histórica». Studia Zamorensia. Segunda Etapa, 2002, vol. 6, p. 257; LuchíA, Corina. «Propiedad comunal y lucha de clases en la Baja Edad Media castellano-leonesa. Una aproximación a la dialéctica de la propiedad comunal». Anales de Historia Antigua, Medieval y Moderna, 2003, vol. 35-36, p. 4 (edición digital); Montaña Conchiña, Juan Luis de la. «Señorialización y usurpaciones terminiegas de espacios realengos: El caso de Badajoz en los siglos XIv-XV». Norba. Revista de Historia, vol. 16, 1996-2003, pp. 353 y ss.; Clemente Ramos, Julián. «La tierra de Galisteo (c. 1375-c. 1425). Transformaciones del poblamiento y apropiaciones ilegales». Arqueología y Territorio Medieval, 2010, vol. 17, pp. 36 y ss.; y, por citar uno más, Diago Hernando, Máximo. «Las ocupaciones de términos en la tierra de Cuenca a fines de la Edad Media: algunas peculiaridades locales de una práctica generalizada en la Corona de Castilla». En VAL Valdivieso, María Isabel y Martínez Sopena, Pascual (eds.). Castilla y el mundo feudal: homenaje al profesor Julio Valdeón. Vol. 3. Valladolid: Universidad de Valladolid, 2009, p. 229. 
USURPACIONES DE TIERRAS COMUNALES EN EL TÉRMINO DE PLASENCIA

A FINES DE LA EDAD MEDIA

M. ${ }^{\mathrm{a}}$ DOLORES GARCÍA OLIVA

Semejante incremento de reclamaciones está relacionado con los progresos realizados en la ocupación del espacio desde la época de la repoblación cristiana. En los inicios, el avance repoblador fue lento y desigual, pues hacia mediados del siglo XIII la escasa población se concentraba en la sexmería del Valle y Trasierra; hacia finales de ese mismo siglo, en parte gracias a la concesión de señoríos, se impulsó la repoblación de la Vera, del territorio comprendido entre el Tajo y el Almonte y del Campo Arańuelo, avanzando así la ocupación de esos espacios en el siglo xIv, aunque todavía a principios del siglo Xv la última zona citada seguía presentando un acusado grado de abandono. Es en esta última centuria cuando la población experimentó un apreciable crecimiento en numerosas aldeas placentinas, crecimiento que se hizo especialmente patente a finales del cuatrocientos ${ }^{2}$.

Dada la base agropecuaria de la economía en la época, el aumento de la población fue acompañado de la ampliación del espacio dedicado al cultivo y a los pastos, incrementándose así la presión sobre la tierra. Esta situación contrastaba con la reducción de los baldíos, debido en parte al propio avance repoblador, pero más aún a la expansión de las dehesas, un proceso alentado por el crecimiento de la ganadería castellana ${ }^{3}$. Apenas tenemos datos que permitan seguir detenidamente cómo se fueron creando las dehesas en el término placentino, una desinformación que afecta también a otros concejos de realengo extremeños, pero no hay dudas de que a finales del siglo xv el espacio adehesado en manos de particulares había alcanzado una notable extensión ${ }^{4}$.

En tiempos de los Reyes Católicos el contraste entre el aumento de la población y la disminución de los bienes de uso comunal probablemente influyó en el aumento de las reclamaciones de las tierras usurpadas, pues cada vez eran menores los espacios de utilización colectiva, por lo que se vigilaban con más celo. Por tanto, el incremento de las denuncias no implica que entonces el fenómeno de las apropiaciones alcanzara mayores proporciones, sino que existía una actitud más reivindicativa.

Conviene señalar que, con frecuencia, las apropiaciones de tierras tuvieron un carácter intergeneracional, pues los descendientes de los usurpadores prosiguieron con

2 Santos Canalejo, Elisa Carolina de. El siglo XV en Plasencia y su tierra. Cáceres: Institución Cultural El Brocense, 1981, pp. 37-40 y 105-107; BernaL EsTÉVEz, Ángel. Poblamiento, transformación y organización social del espacio extremeño (siglos XIII al XV). Mérida: Editora Regional de Extremadura, 1998, pp. 75-78; Clemente Ramos, Julián. «La explotación económica del Campo Arañuelo y la economía rural de la tierra de Plasencia a mediados del siglo XV». Anuario de Estudios Medievales, 2009, vol. 39, n. ${ }^{\circ}$ 1, pp. 257-258.

3 MolÉnAT, Jean-Pierre. «Tolède et ses finages au temps des Rois Catholiques. Contribution à l'historie sociale et économique de la cité avant la révolte des Comunidades». Mélanges de la Casa de Velázquez, 1972, vol. 8, p. 331; Monsalvo Antón, José M. ${ }^{a}$. «Paisaje agrario, régimen de aprovechamientos y cambio de propiedad en una aldea de la tierra de Âvila durante el siglo xv. La creación del término redondo de Zapardiel de Serrezuela». Cuadernos Abulenses, 1992, vol. 17, p. 66; LuchíA, Corina. «Poderes locales, monarquía y propiedad comunal en los concejos de realengo castellanos bajomedievales». Anales de la Universidad de Alicante. Historia Medieval, 2006-2008, vol. 15, p. 224. Esther Pascua, por su parte, señala que en el siglo xv aumentó la tensión entre la Mesta y los concejos por el desarrollo de dos procesos opuestos, la ampliación del espacio adehesado por una parte y, por la otra, la expansión de la ganadería trashumante (PASCUA ECHEGARAY, Esther. «Las otras comunidades: pastores y ganaderos en la Castilla medieval». En RodríGuez, Ana (coord.). El lugar del campesino. En torno a la obra de Reyna Pastor. València: Consejo Superior de Investigaciones Científicas- Universitat de València, 2007, pp. 217-218).

4 García Oliva, Poblamiento, pp. 155 y ss. 
USURPACIONES DE TIERRAS COMUNALES EN EL TÉRMINO DE PLASENCIA

A FINES DE LA EDAD MEDIA

M. ${ }^{\mathrm{a}}$ DOLORES GARCÍA OLIVA

dichas prácticas, continuando una política familiar tendente a incrementar los patrimonios mediante esa vía ${ }^{5}$. Además, también se observa que los bienes usurpados se retenían en poder de los autores de dichos actos, pues hay reclamaciones que afectaban a tierras ya demandadas tiempo atrás. Ello significa que había procesos que se referían a causas anteriores cuyas sentencias no se habían ejecutado en su momento debido a que los usurpadores, amparados en su poder e influencia social, lo impidieron, o bien contaron con la connivencia de funcionarios judiciales para que no se llevaran a efecto los fallos emitidos en su contra ${ }^{6}$. Así pues, la prosecución de las prácticas usurpadoras y/o el incumplimiento de las sentencias también pudieron influir en el aumento de demandas detectado en las últimas décadas del siglo xv, por lo que parece razonable admitir que tal incremento quizá no se corresponde exactamente con un crecimiento paralelo de las apropiaciones.

Otro factor que pudo influir en el aumento de las denuncias es el desarrollo del aparato de la justicia real, una de las manifestaciones de la progresiva centralización monárquica que acompañó al afianzamiento de la dinastía Trastámara ${ }^{7}$. A ello se suma el discurso político de Isabel la Católica, quien se mostraba garante de la recuperación de la justicia y de la restauración de la paz social, pues este mensaje contribuyó a crear un clima de opinión favorable a las reclamaciones, ya que los reyes, además, se identificaron con la defensa formal del realengo ${ }^{8}$. Conviene tener presente este cúmulo de circunstancias para valorar en sus justos términos las numerosas noticias conservadas sobre las apropiaciones de tierras en el término placentino durante el reinado de los Reyes Católicos.

Pese a que la información es más numerosa en esta época, hay que precisar que tiene un carácter parcial, porque las noticias más abundantes proceden de denuncias y/o de algunas diligencias judiciales realizadas, en las cuales no siempre se detalla el motivo concreto del pleito. Es cierto que a veces recogen algunos datos precisos sobre el caso al que se refieren, pero, dado que suelen proceder de una de las partes en conflicto, puede tratarse de una información interesada o que no se ajuste exactamente a la realidad. Además, raras veces conocemos la resolución final. Esta serie de circunstancias influye en que solo podamos hacernos una idea aproximada del alcance que pudo tener la acción usurpadora en Plasencia hacia finales de la etapa medieval.

5 Luchía, «Poderes locales», p. 229 y «Los pleitos por los términos comunales en el concejo de Ciudad Rodrigo en la Baja Edad Media». Historia. Instituciones. Documentos, 2008, vol. 35, p. 277.

6 Luchía, «Poderes locales», p. 225 y «Los pleitos por los términos», p. 282; Plaza de Agustín, Javier. «La usurpación de tierras comunales y baldíos en Guadalajara durante la segunda mitad del siglo Xv». Espacio, Tiempo y Forma. Serie III, Historia Medieval, 2015, vol. 28, pp. 471 y ss.

7 Monsalvo Antón, «Usurpaciones», p. 116.

8 Oliva Herrer, Hipólito Rafael. Justicia contra señores. El mundo rural y la politica en tiempos de los Reyes Católicos. Valladolid: Universidad de Valladolid, 2004, p. 185 y "Conflictos antiseñoriales en el reino de Castilla a fines de la Edad Media: viejas preguntas, ¿nuevas respuestas?». Historia. Instituciones. Documentos, 2009, vol. 36, p. 325. Corina Luchía, por su parte, considera que los campesinos tuvieron habilidad para vincular sus intereses al realengo («Poderes locales», p. 221 y "Los aldeanos y la tierra: percepciones campesinas en los concejos castellanos, siglos XIv-XvI». Studia Historica. Historia Medieval, 2011, vol. 29, p. 220). 
USURPACIONES DE TIERRAS COMUNALES EN EL TÉRMINO DE PLASENCIA

A FINES DE LA EDAD MEDIA

M. ${ }^{a}$ DOLORES GARCÍA OLIVA

1 LAS RECLAMACIONES DE TIERRAS COMUNALES POR PARTE DEL CONCEJO DURANTE EL SEÑORÍO DE DON ÁlVARO DE ZÚNIIGA

Durante las primeras décadas del gobierno de don Álvaro de Zúńiga, quien sucedió a su padre al frente del condado de Plasencia en 1454, no tenemos noticias de que el concejo se interesara por la conservación de la integridad de los bienes comunales; pero esa actitud cambió en los últimos ańos de su vida, cuando ya se había consolidado Isabel como reina de Castilla y se habían aprobado reformas político-administrativas y judiciales tendentes a facilitar su acción de gobierno. Así, en 1483 la ciudad reclamó varias dehesas y lugares del término placentino que don Álvaro había donado a Fernando de Monroy, señor de Belvís, Almaraz y Deleitosa, en gratificación por la ayuda prestada en apoyo de la candidatura de su hijo Juan al maestrazgo de Alcántara'. El concejo trató de recuperar esos bienes por la vía judicial, y Antonio Baena, en calidad de juez de términos, dictó sentencia a su favor en 1482, pero ese fallo fue revocado el ańo siguiente, por lo que se mantuvieron en manos de don Fernando de Monroy hasta la vuelta de la ciudad al realengo ${ }^{10}$. Dado que habían sido entregadas por el titular del señorío de la ciudad, no se trataba en puridad de bienes usurpados por Fernando de Monroy. Otra cosa es que fuera discutible su cesión, y de hecho más tarde, estando ya la ciudad bajo la jurisdicción real, se devolvieron a la misma todos los bienes salvo las dehesas Gato y Rincón, debido a que se trataba de propiedades particulares, las cuales habían sido compradas por el padre del duque.

El concejo emprendió alguna iniciativa más en esa época para recuperar tierras usurpadas. Tenemos noticias de que en 1485 el conde de Nieva recurrió una sentencia en la que se adjudicaba la posesión de la dehesa Las Casas a Losar, aldea placentina; y dos años después, en una provisión relativa a la receptoría de testigos para esta causa, aparecen citados el concejo y su aldea, por lo que cabe presumir que la ciudad también había participado en el litigio desde sus inicios ${ }^{11}$. Las restantes noticias son de carácter general, $\mathrm{y}$ con frecuencia se trata de alusiones que aparecen en testimonios posteriores. En un mandamiento del corregidor dictado en 1494 para hacer un repartimiento destinado a cubrir los gastos realizados en la recuperación de comunales, se indicaba que tales gastos se habían hecho «de diez ańos a esta parte» ${ }^{12}$. Contra esta derrama las villas de seńorío siguieron un largo proceso, como veremos, y entre las alegaciones formuladas aseguraron que no había ninguna cantidad pendiente de pagar de tiempos de los duques, porque entonces la ciudad, además de las rentas de los propios, si era necesario, imponía sisa en la venta de carne, de vino y de otros productos de consumo cotidiano e, incluso, obtenía ingresos de los pastos comunes ${ }^{13}$. Es posible, por tanto, que se hubieran emprendido otras

9 Archivo General de Simancas (en adelante A. G. S.), Registro General del Sello (R. G. S.), 1483.10, 57; 1483.10, 294 y 1483.11, 146. Los bienes entregados fueron la dehesa Espadañal en 1471 y, en 1474, Saucedilla, Casatejada, los lugares de la Campana de Albalá y las dehesas Gato y Rincón. Franco Silva, Alfonso y Pino García, José Luis del. «El señorío de Monroy (siglos xiII-Xv)». En Hernán Cortés y su tiempo. Mérida: Editora Regional de Extremadura, 1987, vol. 1, p. 158.

10 Franco Silva y Pino García, «El señorío de Monroy», p. 158.

11 A. G. S., R. G. S., $1485.02,96$ y $1487.08,31$.

12 Archivo Histórico Provincial de Cáceres (A. H. P. CC.), Legado Paredes, leg. 74, n. ${ }^{o} 3$, fol. $105 \mathrm{r}$.

13 Archivo de la Real Chancillería de Valladolid (A. R. Ch. V.), Registro de Ejecutorias, caja 173.25. 
actuaciones, pero no tenemos información suficiente para determinar cuáles fueron. En los autos de un proceso posterior relativo a los pleitos habidos con las villas de señorío se indica que Antonio Baena, nombrado juez de términos, emplazó a las villas acusadas de usurpaciones y las recibió a prueba, pero no parece que resolviera ninguna denuncia porque la misma fuente señala que después se encomendaron los litigios al bachiller Francés, quien «conosçió» las causas y dictó sentencias ${ }^{14}$. Parece deducirse que el primero inició las pesquisas e, incluso, pudo terminarlas, pero no emitió los correspondientes fallos, algo de lo que se ocupó el bachiller Francés. Pero ello no significa que la actuación de ambos jueces fuera correlativa o, al menos, se plantean razonables dudas al respecto porque este último actuó como tal juez de términos en 1490 y Antonio de Baena, según vimos, lo hizo en 1482, bastantes años antes. A no ser que hubiera vuelto a ser comisionado otra vez unos años después, algo que no parece que fuera frecuente.

Hay otra noticia que alude a que el concejo tomó más iniciativas, pero no contó para ello con el beneplácito de su señor. Así, al menos, se pone de manifiesto en un interrogatorio sobre tierras usurpadas datado en 1506, pues algunos testigos declararon entonces que en tiempos del duque se habían interpuesto demandas, pero el señor de la ciudad obstaculizó la justicia; tal actitud la atribuyeron al hecho de que los condes de Oropesa, Nieva y Miranda, y Fernando de Monroy, señor de Belvís, - presumiblemente los denunciados ese año, aunque en el interrogatorio no se afirma de manera explícita que fueran ellos los acusados en tiempos del dominio de los Estúńiga- eran deudos suyos. Además, los señores de Plasencia habían tomado todas las escrituras de la ciudad, por lo que esta se vio privada de las pruebas documentales adecuadas para apoyar sus reivindicaciones ${ }^{15}$. Así pues, parece que los Estúníiga, en lugar de perseguir las apropiaciones, las permitieron, una actitud comprensible de acuerdo con las relaciones sociales imperantes, pues tal actitud les permitía conservar el apoyo de sus fieles y granjearse más adeptos sin menoscabar su patrimonio, al tiempo que hacía partícipes a sus seguidores del poder que tenía el señor de la ciudad.

\section{LAS REIVINDICACIONES DE TIERRAS USURPADAS A PARTIR DEL REGRESO DE LA CIUDAD A LA JURISDICCIÓN REALENGA}

Hay que esperar, por tanto, a la vuelta de la ciudad al realengo, en 1488, para encontrar una actitud más decidida en aras de la recuperación de tierras o de términos perdidos. La primera actuación tuvo lugar el año siguiente, y la llevó a cabo un particular, Alonso Portocarrero. En la denuncia dirigida a los reyes su procurador expuso que, en tiempos del duque don Álvaro, el señor de Monroy incorporó a sus dominios «grand

14 Ibidem.

15 A. G. S., C. C. P., leg. 15, s. f. Esta información contrasta con la actuación inicial de don Pedro de Estúñiga. En 1442 la ciudad aprobó unas ordenanzas en las que se imponía una tasa al ganado que acudiera a los pastos del Campo Arańuelo con la finalidad de obtener ingresos para reparar la muralla y recuperar las tierras enajenadas, ordenanzas que provocaron la oposición de los seńoríos, pero que fueron respaldadas por el conde (Clemente Ramos, «La explotación», pp. 265-266). 
USURPACIONES DE TIERRAS COMUNALES EN EL TÉRMINO DE PLASENCIA

A FINES DE LA EDAD MEDIA

M. ${ }^{\mathrm{a}}$ DOLORES GARCÍA OLIVA

parte» del término placentino, de manera que una heredad que tenía en dicho término había quedado incluida en el de Monroy, y pidió que se volvieran a poner los mojones en los lugares donde estaban con anterioridad a esa anexión ${ }^{16}$. El documento ratifica la inhibición del duque ante estas prácticas y también pone de manifiesto que el denunciante no quería que su propiedad permaneciera incorporada al término de Monroy, porque en ese caso quedaría sometida a la jurisdicción señorial dado que el titular de la villa extendía sus atribuciones a los confines de su término.

El concejo placentino debió emprender pronto las acciones judiciales contra los usurpadores, pues a finales de 1490 la señora de Garganta la Olla, Pasarón y Torremenga pidió a los reyes que se dictara sentencia en el pleito que la ciudad mantenía con ella por razón de "çiertos términos», porque hacía tiempo que se había concluido, pero el bachiller ante quien pasaba la causa no quería hacerlo, y los monarcas ordenaron a Francisco Francés que dictaminara el pleito, ya que había sido enviado como juez de términos a la ciudad $^{17}$. Ignoramos cuándo se produjo el nombramiento de este juez, pero sabemos que en febrero del año siguiente se le prorrogó la comisión dos meses más, y parece que en julio se le volvió a nombrar de nuevo para desempeñar dicho cometido ${ }^{18}$.

La actuación del bachiller Francés afectó a propiedades de personas particulares, en concreto a las dehesas Herguijuela de la Guadalerna, Valero y Fresnedilla. La primera pertenecía a Diego Gómez de Almaraz y a otros copropietarios, quienes fueron acusados de haber incorporado a la finca tierras pertenecientes a Casas de Millán, aldea del término placentino; el juez de términos ordenó la devolución de la zona reclamada, un fallo que fue recurrido por los acusados, pero no tenemos noticias de actuaciones posteriores relativas a esta causa ${ }^{19}$. Diego de Carvajal, propietario de Valero, fue inculpado por anexionar a su finca la Vega del Berbegón, situada junto al Tajo, al este de Las Corchuelas. La sentencia también fue condenatoria y el acusado apeló de la misma, pero el Consejo la ratificó y ordenó que se entregara a la ciudad de Plasencia la posesión de la zona en disputa ${ }^{20}$. La anexión se había realizado en tiempos de sus antecesores y había afectado a un amplio espacio que comprendía una «tierra muy fragosa e áspera de andar»,

16 A. G. S., R. G. S., $1489.07,89$.

Ibidem, 1490.12, 314.

Ibidem, 1491.02, 79 y 1491.07, 32.

Ibídem, 1491.10, 153 y 1492.08, 170. Para ver la ubicación de este topónimo y de las otras zonas objeto de apropiaciones ilegales, consultar el mapa incluido al final del texto, donde figuran los diferentes señoríos creados en el término de la ciudad de Plasencia y los principales lugares donde se localizan las denuncias de tierras usurpadas en este periodo.

${ }_{20}$ Ibidem, 1491.10, 76; 1492.03, 437 y 439. Hay que advertir que en el primer documento Diego de Carvajal aparece como vecino de Plasencia, pero en los otros dos figura como vecino de Trujillo. En los citados documentos no se aporta ningún dato más sobre este individuo, por lo que carecemos de elementos para decantarnos por una de las dos opciones. Es posible que se tratara de un vecino de esta última localidad, pues en la década de 1490 vivía allí una persona con idéntico nombre (Gerbet, Marie-Claude. La noblesse dans le royaume de Castille. Étude sur ses structures sociales en Estrémadure de 1454 à 1516. Paris: Publications de la Sorbonne, 1979, árboles genealógicos de los Carvajales, sin página), pero no creo que pueda afirmarse con total seguridad, porque el apellido era frecuente en Plasencia, ciudad donde en esos años residía alguien llamado Diego González de Carvajal, y sabemos que no siempre se consignaban los nombres personales de idéntica forma en las fuentes coevas. 
según se dice en los autos del pleito, lo que nos hace pensar en un paraje que apenas había sufrido la acción antrópica. De ello se puede deducir que la ampliación de la dehesa se había hecho sobre tierras deshabitadas o con muy poca población.

En el caso de propiedades situadas junto a baldíos, el método utilizado para ampliarlas fue mediante la incorporación de tierras comunales a las mismas, una práctica más fácil de realizar cuando lindaban con zonas ocupadas por la maleza, como había sucedido en Valero. Pero otra forma de ampliar la propiedad particular fue mediante la anexión de espacios de utilización colectiva pertenecientes a una localidad determinada, una práctica que siguió a la concentración de la propiedad de las tierras de cultivo situadas en el lugar. Esta situación se plasma de manera ejemplar en la petición relativa a la recuperación de tierras usurpadas presentada ante los reyes en 1491 por los concejos de la tierra de Plasencia, por lo que merece la pena reproducir tales palabras:

se sabrá por verdad que antiguamente en la tierra e término de la dicha çibdad auía muchos lugares poblados con sus yglesias, en los quales algunos vecinos dellos que en ellos biuían tenían tierras e haças de pan lleuar, e non de yerua, e los que las tales tierras labrauan e senbrauan no pagauan otra cosa saluo el terradgo de quinze fanegas vna al dueño de la tal tierra e haça. E estos tales dueńos de las dichas tierras e haças las ouieron de vender a personas e caualleros de la dicha çibdad, e los dichos conpradores boluieron e tomaron con ellas otras tierras de lo común e conçegil de la dicha çibdad e su tierra, no auiendo quién ge lo resistiese por ser onbres poderosos; e demás desto hizieron los dichos lugares, e aldeas e haças dehesas e heruajes, e las arrendaron, haziendo arrendamiento de vellota, e pastos, e abrevaderos e casas, de lo qual se an despoblado muchos lugares e aldeas ${ }^{21}$.

Este sistema se documenta en el pleito seguido contra la propietaria de Fresnedilla, lugar situado en las inmediaciones de Cáparra, iniciado ante el juez de términos Francisco Francés en 1491. El fallo inicial adjudicó a la ciudad de Plasencia la posesión de unas tierras incluidas en la dehesa porque se consideró que eran bienes comunales, y fue apelado por Leonor Suárez de Alfaro, la propietaria en ese momento. Pues bien, en las alegaciones presentadas por su procurador se defiende su derecho a la totalidad de la dehesa en base a que sus antepasados habían obtenido la propiedad de las tierras gracias a 17 operaciones de ventas e intercambios, cuyos títulos presentó en el proceso; dado que todas las parcelas habían terminado en manos de su representada, sostenía que el ejido y la dehesa boyal del lugar, bienes que habían sido concedidos a los que tenían heredades allí, también le pertenecían a aquella, puesto que poseía la totalidad de dichas heredades. Este planteamiento no diferenciaba entre el derecho de propiedad, que afectaba a las tierras de cultivo, y el de posesión, aplicable a zonas comunales, una distinción que tuvo en cuenta el bachiller Francés, quien no reconoció que el derecho de propiedad que Leonor Suárez tenía sobre las heredades le hubiera deparado también el derecho de posesión de los espacios comunales adscritos al lugar en exclusiva. El mismo criterio fue seguido por los miembros del Consejo encargados de revisar la sentencia inicial, ya que la ratificaron y fue ordenada su ejecución ${ }^{22}$.

${ }^{21}$ Ibidem, 1491.09, 77 (publicado en García Oliva, Poblamiento, apéndice documental n. ${ }^{\circ}$, pp. 275-277).

22 Ibidem, 1496.02, 127. Sobre este proceso ver García Oliva, Poblamiento, pp. 139-140. 
USURPACIONES DE TIERRAS COMUNALES EN EL TÉRMINO DE PLASENCIA

A FINES DE LA EDAD MEDIA

M. ${ }^{a}$ DOLORES GARCÍA OLIVA

En la carta ejecutoria correspondiente se incluyen los deslindes de la dehesa Fresnedilla, de la que había sido dehesa boyal del lugar, de tierras concejiles y del ejido de Cáparra realizados por el bachiller Francés; también se alude a algunos de los autos del proceso, entre los que se menciona la apelación presentada por el procurador del concejo placentino porque en la primera instancia no se habían restituido también a la ciudad un prado, una parte del término y «çiertas haças mostrencas conçejiles», pero no se vuelve a mencionar esta apelación a lo largo de dicho documento.

Después de la delimitación realizada por el bachiller Francés se deslindaron de nuevo las tierras comunales que se encontraban en la dehesa o confinaban con ella, porque en un documento posterior se hace referencia a deslindes realizados por el licenciado Antonio Cornejo, corregidor en la ciudad en 1494 y 1495, ańos en los que proseguía abierta la causa, y por el licenciado de Vargas, corregidor al menos en 1497, esto es, meses después de emitida la ejecutoria de la sentencia, fechada en 1496. Esta información se encuentra en una pesquisa realizada en 1514 sobre las delimitaciones de los comunales situados en Fresnedilla, la cual parece que fue desencadenada porque los propietarios de la dehesa tenían ocupada el haza denominada Pozo de los Mozos²3. Según el interrogatorio propuesto esta última vez y la declaración de los testigos, parece que el haza había sido deslindada en su momento, por lo que cabe deducir que se había vuelto a producir la ocupación de esa parcela, hecho que corrobora la continuación de las acciones usurpadoras.

Otro de los investigados por semejantes prácticas fue Fernando de Monroy, señor de Belvís. Este, probablemente aprovechando el ejercicio del poder jurisdiccional que le cedió el duque sobre varios lugares del Campo Arańuelo, procuró aumentar su patrimonio inmueble mediante la ampliación de alguna de sus dehesas a costa de bienes comunales limítrofes, o se atribuyó la propiedad de otras. Ya en 1490 los lugares de la tierra denunciaron que había incorporado una dehesa boyal de Millanes y Casarejo y un pedazo de tierra concejil de Saucedilla y Casatejada a la dehesa Espadañal, donada también por el duque al señor de Belvís; y pidieron que, dado que dichos lugares y la dehesa habían sido restituidos a la ciudad, les fueran devueltas las tierras que Fernando de Monroy había anexionado a la citada dehesa. La recuperación de las tierras reclamadas no fue inmediata, ya que siguieron integradas en la dehesa Espadañal, y al ańo siguiente los concejos afectados tuvieron que pedir su devolución de nuevo, encomendando la resolución de la demanda al juez de residencia ${ }^{24}$. También creó la dehesa Mesa y Vega sobre tierras de uso común de Romangordo, un espacio que fue restituido a la Campana de Albalá por el juez de términos Francisco Francés en torno a $1491^{25}$.

El bachiller Francés y, quizás también, otro justicia que interviniera después, debieron pronunciar sentencias condenatorias contra los seńoríos enclavados en el término, pues entre finales de 1490 y 1494 los señores y los concejos de las villas de Valverde, Garganta la Olla, Pasarón, Torremenga, Jarandilla, Tornavacas, Belvís, Almaraz y

A. G. S., C. C. P., leg. 15 , s. f.

24 A. G. S., R. G. S., $1490.11,65$ y $1491.03,181$.

25 Ibidem, 1491.12, 175. En este documento la dehesa aparece con el nombre Mesa Vieja de Albalá, pero en otros se denomina Mesa y Vega (1492.02, 277; 1494.02, 452 y 1498.02, 106). 
USURPACIONES DE TIERRAS COMUNALES EN EL TÉRMINO DE PLASENCIA

A FINES DE LA EDAD MEDIA

166

M. ${ }^{\mathrm{a}}$ DOLORES GARCÍA OLIVA

Deleitosa presentaron varias apelaciones ${ }^{26}$. Por lo general, no conocemos los términos precisos de esos pleitos ni la resolución final, ya que solo contamos con una información parcial que, además, no siempre es coincidente. Buena parte de los datos reunidos se encuentran recogidos en los autos del litigio mantenido entre Plasencia y las villas de señorío porque estas se negaron a contribuir en los gastos de los pleitos incoados por la ciudad para la recuperación de los términos usurpados, a pesar de que participaban en el aprovechamiento de recursos de utilización colectiva juntamente con los vecinos del realengo. Así, en un mandato dirigido en 1494 por el corregidor a las villas de señorío, ordenándoles que contribuyeran en dichos gastos, se indica que la villa de Valverde había ocupado más de 4 leguas del término placentino y la de Serrejón 3 leguas; sin embargo, en otra diligencia ante el mismo corregidor el procurador placentino afirmó que se habían recuperado más de dos leguas de término de cada una de dichas villas, además de otras zonas ocupadas por el resto de los lugares de señorío ${ }^{27}$. La falta de concordancia de las cifras puede deberse a que una cantidad correspondía a lo reclamado y otra a lo recuperado, o también a que la información ofrecida en ambas diligencias no tenía rigor. En cualquier caso, esta constatación pone de manifiesto que los datos recopilados pueden carecer de exactitud y, en consecuencia, deben tomarse con cautela. Por otra parte, hay que considerar también que algunos procesos no habían concluido, pues el repartimiento incluía una cantidad destinada a continuar aquellos que aún estaban pendientes, y en estos casos cabía la posibilidad de que la sentencia definitiva no adjudicara la totalidad de las tierras en litigio a la ciudad.

Encontramos una información de signo opuesto en las alegaciones de los procuradores de las villas de señorío oponiéndose a que sus partes estuvieran obligadas a participar en el citado repartimiento. En este caso hacían hincapié en que no se había recobrado ningún término o, a lo sumo, pequeñas extensiones o zonas próximas a la ciudad de las que los hombres dependientes de señorío, por su lejanía, no se solían aprovechar. Por ejemplo, el procurador de Garganta la Olla afirmó que, si algo se había recuperado, habían sido unas tierras cerca de la ciudad, ocupadas por algunas personas particulares, y en otro segundo escrito declaró que no se había recobrado nada para pasto común; el de Serrejón se manifestó en términos semejantes, pues señaló que no se había restituido

26 Ibidem, 1491.01, 47 y 1492.02, 97 (Valverde); 1490.12, 314; 1491.12, 244; 1492.09, 181; 1493.09, 78 y 1494.10, 436 (Garganta la Olla, Pasarón y Torremenga); 1492.01, 69 (Jarandilla y Tornavacas), 1491.06, 113 (Belvís, Almaraz y Deleitosa).

27 A. R. Ch. V., Registro de Ejecutorias, caja 173.25. La relación completa de la tierra recobrada por la ciudad que figura en el mandamiento del corregidor Antonio Cornejo es la siguiente: de don Pedro de Zúñiga, señor de Valverde, más de 4 leguas; de Fernando de Monroy, señor de Belvís, 6 o 7 leguas; de Bernardino de Velasco, condestable de Castilla, 3 leguas alrededor de Serrejón y 2 alrededor de Talaván; del obispo y cabildo de Plasencia 2 leguas próximas a Jaraicejo; de Francisco de Carvajal, 2 leguas cerca de Torrejón; de Gonzalo Bermúdez, 2 leguas alrededor de Las Corchuelas, Monfragüe y Grimaldo; de Fernando de Monroy, señor de Monroy, 2 leguas alrededor de Monroy; de don Francisco de Zúñiga, 2 leguas alrededor de Mirabel; de la condesa de Pasarón, 2 leguas alrededor de Pasarón y Torremenga; del señor Fonseca, 1 legua alrededor de Garganta la Olla; y del conde de Oropesa, 3 leguas alrededor de Jarandilla y Tornavacas $(A$. $H$. P. CC., Legado Paredes, leg. 74, n. ${ }^{\circ} 3$, fol. 105v). En el mapa donde se enumeran las tierras usurpadas no se reflejan estas apropiaciones realizadas por los señores del término placentino porque se desconoce a qué zonas concretas afectaron. 
USURPACIONES DE TIERRAS COMUNALES EN EL TÉRMINO DE PLASENCIA

A FINES DE LA EDAD MEDIA

M. ${ }^{\mathrm{a}}$ DOLORES GARCÍA OLIVA

nada, «salvo sy hera un pedaço de roble que hera en çierto lugar», indicando además que de esa zona se aprovechaban los vecinos de la villa antes de que Plasencia la recuperase; los procuradores de las villas que siguieron el pleito hasta el final alegaron que, si se había producido alguna apropiación, habría sido realizada por «regidores e otras personas prinçipales de la dicha çibdad, los quales syn costa alguna dexaran los dichos valdíos, sy no los quisyeran dexar los devieran condepnar en costas, e por ser ellos mismos del conçejo e por les faboresçer e ayudar se las soltaran o dieran lugar a que no fuesen condepnados en ellas», y en otro auto del proceso aludieron a que se habían recobrado «los pedaços de las dehesas que algunos vezinos e regidores de la dicha çibdad tenían tomados e ocupados»; solo el procurador de Talaván aportó un dato concreto, el de la recuperación de «un término que se dezía el Yglejuela», situado al norte del Tajo, pero defendía que sus partes no debían pagar en los gastos de tal proceso porque no utilizaban esas tierras, situadas al otro lado del Tajo ${ }^{28}$. Por su localización, es probable que se trate de Herguijuela de la Guadalerna, una dehesa que, según vimos antes, había incorporado tierras pertenecientes a Casas de Millán, aldea del concejo placentino. Dado que se trata de alegaciones orientadas a la defensa de sus representados, no se pueden tomar esas palabras en sentido literal, puesto que responden a la estrategia seguida para lograr su exculpación. Por ello no admitían que se hubieran recuperado tierras comunales o se minimizaban su alcance y los beneficios derivados de dicha recuperación para el común de vecinos; asimismo, daban la imagen de que ninguna villa de señorío había sido condenada por semejantes delitos, puesto que relacionaban las usurpaciones con dehesas de regidores y de otras personas importantes de la ciudad, circunstancia que utilizaron además para apuntar la actitud connivente del concejo con la intención de debilitar la reclamación de la parte adversa.

Ya he señalado que apenas tenemos información sobre los procesos mantenidos, pero hay indicios que invitan a desconfiar de la idea que transmiten los procuradores, como es la presentación de apelaciones por algunos concejos de señorío, solos o junto a sus señores, como antes señalé. Y en los mismos autos del proceso al que me estoy refiriendo los procuradores de las villas corroboran esa realidad. Defendieron, entre otros argumentos utilizados, que sus representadas no tenían que participar en el repartimiento porque la mayoría de los pleitos se habían hecho contra ellas; las villas de señorío se habían ocupado de defender cada una su jurisdicción, por lo que no era justo que tuvieran que contribuir también en los gastos realizados por la ciudad, sino que esta debería hacer frente a los suyos, al igual que ellas.

Admitían que las villas debían contribuir con la ciudad solo en el caso de que fueran aumentados los pastos y espacios de utilización común, algo que negaban que hubiera sucedido o, en el mejor de los casos, concedían que solo se habían recuperado pequeñas zonas situadas, además, lejos de los lugares de señorío, como hemos visto. Pero la escasez de las recuperaciones se debía a que las sentencias estaban recurridas, un argumento que también utilizaron para oponerse a la contribución en la derrama en base a que los pleitos no se habían concluido. Por otra parte, en el supuesto de que se hubieran producido recuperaciones de tierras en otros casos, ello tampoco habría redundado en beneficio de sus partes debido a que "por las dichas que se dezían sentencias no se atribuyeran

28 A. R. Ch. V., Registro de Ejecutorias, caja 173.25. 
más derecho ni prouecho a los moradores de la tierra que de antes comían, e paçían, e podían comer e paçer los dichos términos que dezían recobrados, como después de las dichas sentencias, lo qual nunca les fuera perturbado ${ }^{29}$. Desde luego, si, como parece, no se trataba de apropiaciones realizadas por particulares sino de tierras anexionadas por los diferentes concejos, los habitantes de los respectivos lugares, efectivamente, seguirían utilizando las zonas ocupadas por cada seńorío, pero no el conjunto de los vecinos de la tierra, como pretendían dar a entender los procuradores.

Algunas de las alegaciones fueron admitidas, pues se ordenó que los concejos no contribuyeran cada uno en el pleito que la ciudad llevaba contra él, y también se ordenó que se presentaran las cuentas de manera detallada, porque los procuradores de las villas sospechaban que la ciudad pretendía que los lugares de señorío abonasen la totalidad de los gastos, aparte de que era imprescindible para cumplir con el punto anterior. Las sospechas no eran infundadas en relación con la petición inicial, en la que el procurador de la ciudad evaluó los gastos realizados en 1.500 .000 mrs y 200.000 mrs más para proseguir los pleitos inacabados, cantidades de las que correspondería pagar la mitad a las villas de señorío; pues bien, de acuerdo con las cuentas realizadas por las personas designadas por el corregidor Antonio Cornejo, se tasaron los gastos en 525.649 mrs y añadieron otros $100.000 \mathrm{mrs}$ para acabar los procesos ya iniciados, de los cuales correspondía pagar a la ciudad 421.270 y el resto a los señoríos ${ }^{30}$.

Antes de llegar a esa conclusión, el corregidor ordenó a las villas de señorío que enviaran sus procuradores con los padrones respectivos para hacer el reparto, una orden que fue acatada por los concejos de Jaraicejo, Mirabel, Serrejón y otros, que no especifica, pero los de Jarandilla, Tornavacas, Pasarón, Torremenga, Belvís, Almaraz y Deleitosa respondieron que no estaban obligados a ello porque, cuando se hicieron los gastos, no habían sido consultados ${ }^{31}$. Claramente se observa que no todas las villas tenían el mismo criterio, y esto se pone de manifiesto también en el transcurso del pleito mantenido por este motivo. En las diligencias iniciales aparecían implicados todos los lugares de señorío, y en los autos primeros encontramos que intervinieron procuradores de varios de ellos, pero lo prosiguieron hasta el final solo Valverde, Jarandilla, Tornavacas, Pasarón y Torremenga. Dado que en la sentencia definitiva se falló que los habitantes de esas villas debían pagar la parte que les correspondía, se deduce que el resto de los lugares de señorío habían optado por abonar la suya antes de finalizar esta causa, la cual se prolongó hasta 1502. La cantidad final asignada a estas villas fue de $120.880 \mathrm{mrs}$, de los cuales se ordenó descontar a cada una los gastos que había realizado en los pleitos que la ciudad mantuvo con ellas, y también se descontaron 27.380 mrs correspondientes a causas relativas a jurisdicción y no a términos porque en ellas no debían pagar aquellas ${ }^{32}$. De ello se deduce

29 Ibidem.

30 A. H. P. CC., Legado Paredes, leg. 74, n. ${ }^{\circ}$ 3, fol. 106v. El reparto se hizo de acuerdo con el número de vecinos existente en los diferentes lugares, los cuales se elevaban a 5.920 en las tierras de realengo y a 3.635 en las de señorío según el citado documento.

31 Ibidem, fol. 106r.

32 A. R. Ch. V., Registro de Ejecutorias, caja 173.25. Las cantidades asignadas a cada lugar en esta sentencia y las atribuidas por el corregidor Antonio Cornejo (A. H. P. CC., Legado Paredes, leg. 74, n. ${ }^{\circ} 3$, fols. 107r-108r) son las siguientes: 
USURPACIONES DE TIERRAS COMUNALES EN EL TÉRMINO DE PLASENCIA

A FINES DE LA EDAD MEDIA

M. ${ }^{a}$ DOLORES GARCÍA OLIVA

que la mayoría de los pleitos habían tratado sobre términos, no sobre jurisdicción, en contra de lo que habían defendido los procuradores de las villas.

Todos los señoríos se vieron involucrados en la usurpación de términos, por lo que se comprende que no fueran partidarios de contribuir a sufragar los gastos generados por la recuperación de baldíos por parte de la ciudad, y también que centraran el foco de las acusaciones en caballeros y otras personas de la ciudad, pero no en ellos. Pero, dada la creciente presión sobre la tierra, en ocasiones sus intereses se vieron lesionados por prácticas abusivas realizadas por otros seńoríos colindantes o propietarios de tierras, y en semejante situación no dudaron en denunciar las ilegalidades cometidas por otras personas. Es el caso de Fernando de Monroy y de su villa homónima, quienes en 1492 acusaron a Talaván de haber incorporado a su término una vereda que discurría entre ambas villas, cobrar derechos de portazgo a los que transitaban por ella y también de haber ocupado y labrado parte del término de Monroy, por lo que se dirigieron a los reyes para que hicieran justicia ${ }^{33}$.

Unos años después, en 1498, el procurador de las villas de señorío acusó al monasterio de San Vicente, de Plasencia, de haber incorporado tierras concejiles a la dehesa Macarra, la cual le había dado la duquesa de Plasencia. En este caso la usurpación no solo obedecía a la obtención de más pastos, sino también de abrevaderos, pues en la denuncia se indica que los frailes se habían apropiado de «vn pedaço de tierra junto con lo de la villa de Serrejón, a do dizen el arroyo de Valbuena (...) en que diz que tomaron el mejor abreuadero que ay en toda aquella tierra ${ }^{34}$. El mismo interés de conseguir aguaderos para el ganado pudo estar presente en la ampliación de la dehesa Valero, antes vista, puesto que su propietario incorporó la vega del Berbegón y llevó los límites de la dehesa hasta el Tajo, y también se ha documentado en otra zona de la geografía extremeña ${ }^{35}$. Es cierto que, por lo general, el agua era un bien de uso común, pero no era raro que los propietarios de las dehesas obstaculizaran el acceso a ella de otros ganados ajenos a la explotación de la finca, y de hecho en la denuncia se dejaba constancia de que se penalizaba a las reses que entraban en ella.

Las denuncias de la ciudad y/o de sus aldeas se repitieron a principios del siglo XVI, dirigiéndose con frecuencia a los mismos seńoríos que habían sido acusados años atrás de

\begin{tabular}{|c|c|c|c|}
\hline Lugar & $\begin{array}{c}\text { Repartimiento inicial } \\
\text { (Antonio Cornejo) }\end{array}$ & Sentencia definitiva & $\begin{array}{c}\text { Descuento por pleitos } \\
\text { de la ciudad con cada villa }\end{array}$ \\
\hline Valverde & $32.700 \mathrm{mrs} 2$ corn & $32.216 \mathrm{mrs}$ & $10.000 \mathrm{mrs}$ \\
\hline Jarandilla & $27.583 \mathrm{mrs} 4$ corn & $25.215 \mathrm{mrs}$ & $8.000 \mathrm{mrs}$ \\
\hline Tornavacas & $13.791 \mathrm{mrs} 4$ corn & $12.680 \mathrm{mrs}$ & $4.000 \mathrm{mrs}$ \\
\hline Garganta la Olla & $13.791 \mathrm{mrs}$ & $12.680 \mathrm{mrs}$ & $3.000 \mathrm{mrs}$ \\
\hline Pasarón & $13.080 \mathrm{mrs}$ & $12.114 \mathrm{mrs}$ & $5000 \mathrm{mrs}$ \\
\hline Torremenga & $567 \mathrm{mrs} 4$ corn & $757 \mathrm{mrs}$ & \\
\hline
\end{tabular}

33 A. G. S., R. G. S., 1492.05, 614.

34 Ibidem, 1498.10, 266.

35 La Orden de Alcántara intentó ampliar su dehesa Cantillana, colindante con Media Cacha, dehesa particular situada en el término cacereño, hasta el arroyo Valdeliso, de manera que las dos partes pudieran acceder a sus aguas (GARcía Oliva, Organización, p. 108). 
USURPACIONES DE TIERRAS COMUNALES EN EL TÉRMINO DE PLASENCIA

A FINES DE LA EDAD MEDIA

esas prácticas, pero no siempre podemos precisar si se trataba de nuevas acciones o es que no se habían recuperado tierras usurpadas ańos atrás. Ya en 1503 el concejo placentino acusó a Francisco de Monroy, señor de Belvís, Almaraz y Deleitosa, y a su abuela de haber ocupado baldíos en Campo Arańuelo y de vender sus pastos a serranos, dato que pone de manifiesto que la demanda de invernaderos podía alentar las usurpaciones de tierras por particulares $^{36}$. El año siguiente Alonso de Cáceres, procurador del concejo placentino, pidió que el corregidor investigara qué tierras estaban ocupadas por caballeros y señores comarcanos, pero esta iniciativa no debió tener eco porque en 1505 los concejos de la tierra de Plasencia denunciaron ante la reina que, desde hacía tiempo, estaban ocupados parte del Campo Arańuelo, un pedazo de tierra cerca de Jarandilla, otro hacia la sierra de Valverde de la Vera, otro en el límite con Candeleda, uno más lindando con el término de Granadilla, y «otras muchas tierras e términos entre el monte e el río de Tejo y el río de Tiétar, i desde el río de Tiétar fasta la syerra de la Vera e valle de la dicha çibdad ${ }^{37}$, palabras que hacen extensibles las apropiaciones a todo el término. Tales abusos habían sido realizados por concejos y por personas particulares de la tierra y de otras partes de fuera de la ciudad, según se dice en la exposición del documento, pero en el dispositivo se menciona también a regidores, caballeros, escuderos y otras personas como autores de las usurpaciones. Para hacer justicia la reina nombró juez de términos al licenciado Vergara en julio de 1505 y le dio un plazo inicial de 80 días, pero la comisión fue prorrogada tres veces más. La última de la que tenemos noticias fue en abril del año siguiente, momento en el que le concedieron 100 días más debido a que, si bien ya había restituido algunos bienes a la ciudad, la mayoría de los procesos estaba aún sin concluir por entonces ${ }^{38}$. Si tenemos en cuenta que, según la denuncia, las usurpaciones afectaban a buena parte del término placentino y que el número de infractores era elevado, se comprende que necesitara un periodo de tiempo tan prolongado.

Sin embargo, las noticias sobre su actuación no son numerosas. Sabemos que se ocupó de un litigio seguido contra Belvís y Deleitosa, lugares de Francisco de Monroy, a los que se había acusado de haber ocupado Garganta Honda, Valdelloso, La Parrilla y Salgado, tierras próximas a Higuera; y pronunció una sentencia en contra de Alfonso Esteban, vecino de Jaraíz, por haberse apropiado de Yedra, una tierra situada entre la citada aldea y Torremenga, la cual deslindó ${ }^{39}$.

Los progresos realizados en la recuperación de las tierras usurpadas debieron ser lentos a tenor del interrogatorio propuesto por Alonso de Cáceres, procurador de la ciudad, al corregidor en marzo de 1506, un mes antes de que se concediera la última prórroga al licenciado Vergara. Las preguntas contenidas en dicho interrogatorio ofrecen una amplia información sobre las tierras reclamadas, pues en él se identificaba a varias villas y señores como autores de apropiaciones de tierras realengas, proponiendo en algunos casos

36 A. G. S., C. C. P., leg. 15, s. f. Ya hace décadas que Emilio Cabrera detectó que uno de los motivos que animó a la usurpación de tierras fue el arrendamiento de los pastos a ganaderos foráneos («Usurpación», p. 43).

37 A. G. S., C. C. P., leg. 15, s. f.

38 Ibidem.

39 Ibidem. 
USURPACIONES DE TIERRAS COMUNALES EN EL TÉRMINO DE PLASENCIA

A FINES DE LA EDAD MEDIA

M. ${ }^{a}$ DOLORES GARCÍA OLIVA

preguntas sobre bienes concretos usurpados. Estas se referían a la villa de Candeleda, a la que se acusaba de tener ocupado el espacio comprendido entre las gargantas de Alardos y Chilla; a la villa de Serrejón se le atribuía haberse apropiado de los lugares de Anguila y Oliva y de otros términos, sobre los cuales había sentencias a favor de la ciudad; se acusaba a Talaván de haberse apoderado de una cañada y de unas tierras próximas a su término pertenecientes a Plasencia; también se citaba a las villas de Belvís y Almaraz, con las que se mantenían pleitos iniciados tras el regreso de la ciudad al realengo; y se atribuía a las de Valverde, Jarandilla, Tornavacas, Garganta la Olla, Pasarón y Torremenga la ocupación de términos, baldíos, pastos, montes y/o abrevaderos ${ }^{40}$.

En el interrogatorio se indica que la zona comprendida entre las gargantas de Alardos y Chilla había sido cedida por la ciudad de forma vitalicia a Fernando Pérez de Monroy, quien se había comprometido por sí y por sus herederos a dejarla libre a su muerte, según constaba en un documento de 1341 firmado por el beneficiario. Ignoramos si se cumplió el compromiso, pero en una confirmación otorgada por Enrique II a Candeleda en 1373 aparece esa zona incluida en el término de dicha villa ${ }^{41}$. La ciudad la reclamó en 1431 ante el juez comisionado por Juan II para resolver los pleitos por usurpaciones y, según vemos, ahora planteó de nuevo la reclamación. Tal reivindicación se fundaba en los límites asignados a Plasencia por Alfonso VIII en 1189, donde se citaba expresamente la garganta de Chilla como confín nororiental, pero no prosperaron las demandas debido a que Candeleda contaba con el citado documento de Enrique II, y ese espacio no volvió a la jurisdicción placentina ${ }^{42}$.

En el caso de Belvís y Almaraz se indica que los litigios se habían iniciado después de la vuelta de la ciudad al realengo y que se había fallado en primera instancia a favor de la ciudad, pero la parte adversa había apelado de las sentencias y los procesos estaban sin concluir. No sabemos si se trataba de los mismos litigios cuyos fallos se habían recurrido ya en 1491, lo que denotaría la enorme lentitud de la justicia, o si se trataba de otros incoados posteriormente. En este supuesto, aparte de que también se pudiera haber demorado la resolución de los pleitos si llevaban años pendientes, evidenciaría la reincidencia de dichas villas en las infracciones. También es posible que la ocupación de la cańada atribuida a Talaván se remonte en el tiempo, pues en 1492 el señor de Monroy denunció que se había anexionado una vereda a ese término, y aunque no se utilice la misma denominación en ambos casos, el hecho de tratarse de vías pecuarias invita a considerar esa posibilidad.

No tenemos noticias sobre lo sucedido en el resto de los casos, pero pudieron producirse situaciones parecidas a las sugeridas para Belvís y Talaván, es decir, que se tardaran en resolver los litigios o se reiteraran las usurpaciones. Así, en 1512 se pidió que se enviara al Consejo la información reunida sobre las querellas pendientes con Jarandilla

40 Ibidem.

41 Luis López, Carmelo. «Las comarcas meridionales de la tierra abulense medieval: precisiones a una problemática delimitación y repoblación». Studia Historica. Historia Medieval, 2002-2003, vol. 20-21, p. 36.

42 Sánchez Loro, Domingo. Historias placentinas inéditas. Primera parte, Catalogus ecclesiae placentinae. Vol. C. Cáceres: Institución Cultural El Brocense, 1985, p. 394; A. G. S., C. C. P., leg. 15, s. f. El privilegio de Alfonso VIII está publicado por Sánchez Loro, Domingo. Historias placentinas inéditas. Primera parte, Catalogus ecclesiae placentinae. Vol. A. Cáceres: Institución Cultural El Brocense, 1982, pp. 33 y ss. 
y Tornavacas, villas del conde de Oropesa que aparecían citadas en el interrogatorio de 1506, pero no se especifica de qué causas se trataba ni se aporta ningún dato que permita averiguar cuándo se inició la reivindicación correspondiente ${ }^{43}$.

Según vimos antes, en 1514 los propietarios de Fresnedilla tenían ocupado de nuevo el haza denominada Pozo de los Mozos. Al año siguiente se mantuvo un pleito con los herederos de Antón Bote, Pedro Bote y otros vecinos de Jaraíz, por Yedra, una heredad devuelta por el licenciado Vergara a la ciudad de Plasencia, y Salgado, tierras que fueron adjudicadas de nuevo a Plasencia ${ }^{44}$. El hecho de que años después se mantuviera un litigio por la misma propiedad puede ser debido a que la sentencia inicial había sido recurrida, no se había llegado a ejecutar o se había vuelto a ocupar la misma zona, pero la información reunida no permite optar por alguna de las posibilidades. Es cierto que los nombres de los inculpados en los dos casos no coinciden, pero la noticia segunda se refiere a dos zonas y no se identifica a todos los imputados, por lo que no se puede descartar que también estuviera implicado Alfonso Esteban, inculpado la vez anterior, o sus herederos. Por otra parte, si bien el juez de términos solía actuar de acuerdo con lo dispuesto al respecto en las Cortes de Toledo de 1480, ley que permitía agilizar los pleitos sobre usurpaciones de tierras, la norma salvaguardaba también los derechos de propiedad de los acusados, quienes podían apelar a instancias superiores para defender sus derechos, y semejante facultad deparaba la dilación de los procesos ${ }^{45}$. Es decir, en el caso de Yedra cabe la posibilidad de que hubiera sido apelada la sentencia inicial y el litigio se hubiera prolongado hasta 1515. Pero no he localizado información para dilucidar este punto. Lo que sí es destacable en estos dos casos, los de Yedra y Salgado, es que los autores de estas usurpaciones no eran titulares de señoríos o caballeros destacados de Plasencia, como hemos visto hasta ahora, sino aldeanos, quizá miembros del sector más acomodado del campesinado.

En torno a 1516, asimismo, los sexmeros denunciaron que las villas de Torrejón y de Las Corchuelas tenían tomados «muchos términos, e pasto, e labor e juridiçión»; si recordamos los datos antes expuestos, en las diligencias realizadas entre 1494 y 1496 sí se atribuía a ambas villas la ocupación de baldíos placentinos, pero no aparecen en la relación de imputados que se incluye en el interrogatorio de 1506; de acuerdo con ello, podemos pensar que esta última acusación obedecía a nuevas acciones ilegales cometidas por los denunciados, hecho que significaría que tal actividad había proseguido en los inicios de los Tiempos Modernos, pero carecemos de apoyo documental también en este caso para confirmar ese supuesto ${ }^{46}$.

Hacia ese año se producen denuncias de nuevas usurpaciones. En un memorial de agravios elevado por los sexmeros de la tierra placentina al rey se decía que las dehesas

43 A. G. S., C. C. P., leg. 15, s. f.

44 Ibidem.

45 Cortes de Toledo de 1480, art. 82, en Cortes de los antiguos reinos de León y de Castilla. Madrid: Sucesores de Rivadeneyra, 1882, t. IV, pp. 154-157. Sobre el contenido y aplicación de la ley ver, entre otros, los trabajos de Carmona Ruiz, Usurpaciones, pp. 91-96; Pino García, José Luis del. «Pleitos y usurpaciones de tierras realengas en Córdoba a fines del siglo xv: la Villa de las Posadas». Estudios de Historia de España, 2010, vol. 12, n. ${ }^{\circ} 1$, pp. 126 y ss.; Jara Fuente, "Que memoria de onbre», pp. 83-84.

46 A. G. S., C. C. P., leg. 15 , s. f. 
USURPACIONES DE TIERRAS COMUNALES EN EL TÉRMINO DE PLASENCIA

A FINES DE LA EDAD MEDIA

M. ${ }^{\mathrm{a}}$ DOLORES GARCÍA OLIVA

Hatena, Chistes, Rodesnera, situadas en la zona de Torrejón y Las Corchuelas, y otras confinaban con la jara según sus antiguos deslindes, «y de poco tiempo acá los dueños dellas an desmontado mucha parte de la xara por estender más los límites, diziendo que llegan hasta la xara, e lo intentan defender ${ }^{47}$, palabras que no dejan lugar a dudas sobre lo reciente del hecho. El citado memorial no lleva fecha, pero en él se dice que los propietarios de dehesas habían aumentado las penas impuestas a los que cortaban leña «agora, después quel liçençiado Ortiz es corregidor» y, si bien ignoramos cuándo empezó a desempeñar este cargo, sabemos que al menos en 1516 estaba actuando como tal; también se alude a la existencia de una sisa de 200.000 mrs para una obra pública y en febrero de ese mismo año, 1516, se solicitó su supresión debido a la carestía existente entonces, por lo que el escrito debió de redactarse hacia esa época. En el margen de este apunte se anotó, probablemente por parte de algún miembro del Consejo, "comisyón a una persona por la ley de Toledo en lo que oviere lugar, y sy no por vía ordinaria», y tenemos noticias de que se envió un juez de términos ese mismo año a la ciudad para deslindar las dehesas situadas entre los ríos Tajo y Almonte, cuyos propietarios se habían anexionado un espacio que «dura de largo quatro leguas e dos leguas casy de ancho» ${ }^{48}$, según expuso el concejo de Serradilla.

La noticia del nombramiento del juez nos ha llegado porque Antonio de Monroy, seńor de la villa homónima y propietario de dehesas en esa zona, consiguió que los reyes encomendaran el deslinde de sus fincas al corregidor en lugar de que lo hiciera el licenciado Medina, el juez a quien previamente habían comisionado para juzgar las denuncias. El motivo aducido por el señor de Monroy era que así se haría con menos coste para la ciudad, pero tal argumento fue refutado por el concejo de Serradilla, quien suplicó a los reyes que revocaran el último mandato y que la pesquisa fuera realizada por el juez de términos, como se había dispuesto inicialmente. En apoyo de su petición el concejo citado alegó que solo se había encomendado al corregidor el deslinde de las dehesas de Antonio de Monroy, por lo que el juez de términos tenía que seguir actuando en el resto de los casos; además, en una de las dehesas, Saucedilla la Hondonera, Antonio de Monroy era solo copartícipe, por lo que tendrían que intervenir los dos magistrados en ese caso, elevándose considerablemente los gastos del proceso. Pero, sobre todo, el concejo serradillano hizo hincapié en que era improcedente encomendar el deslinde al corregidor debido a que su imparcialidad era cuestionable dada la interferencia de relaciones personales, exponiendo en este punto consideraciones que afectaban al conjunto de los propietarios y otras relativas específicamente al señor de Monroy. En este sentido advirtió que muchas de las propiedades investigadas eran de «regidores y de los prinçipales de Plazençia», por lo que el corregidor se plegaría a su voluntad para evitar tener problemas luego en el juicio de residencia, y afirmaba que, en el caso de que interviniese, «sería para más agraviar al dicho conçejo y dar a los herederos de dehesas títulos de lo que no los tienen", unas palabras que ponen de manifiesto la sospecha de que su actuación no sería imparcial. Antonio de Monroy, quien tenía ocupado «más parte de los baldíos que todos los otros dueños de dehesas», según se dice en el documento, no era regidor, pero tenía deudos y

47 Ibidem.

48 Ibidem. 
parientes regidores, y además era yerno del licenciado Francisco de Vargas, del Consejo Real, y deudo de otros del mismo Consejo, y el corregidor procuraría congraciarse con ellos; como prueba de la confabulación existente entre ellos indica que adjuntaba unas cartas mensajeras remitidas por el corregidor al doctor Carvajal y al licenciado Zapata, miembros también del Consejo Real, sobre este asunto ${ }^{49}$. La desconfianza que tenía el concejo de Serradilla sobre la imparcialidad del corregidor queda de manifiesto en estas elocuentes palabras:

syn enbargo de lo ansý proveýdo, vuestra alteza mande al dicho licenciado Diego de Medina fenezca el dicho mojonamiento segund que por vuestra alteza le fue cometido, e sy otra cosa fueren seruidos prover o ynovar, vuestras altezas, como reyes e señores naturales, pueden hazer merçedes de los vasallos e sus haziendas e de los términos, e por esta vía es darles título a ello, pero el dicho conçejo no entiende ante corregidor de Plazençia ni por otra vía pedir justicia, más de por aquella de que vuestra alteza al prinçipio les provió, y ansí lo protestan de no la pedir antel corregidor, antes la dexar perder, y sería a cargo de vuestra real conçiençia ${ }^{50}$.

Según se observa, el concejo estaba dispuesto a abandonar la causa si no se revocaba la provisión dirigida al corregidor, pues estaba convencido de que difícilmente alcanzaría justicia ante él debido a la elevada posición social de don Antonio de Monroy, su importante red de influencias y la connivencia de aquel con los regidores y notables de la ciudad. Y pone de manifiesto que él procuraba la conservación del realengo, algo que solo dependía de la decisión real. Asimismo, en otro escrito advertía que la separación del juez de términos de esa causa podía ocasionar daños al realengo, el cual los aldeanos procuraban conservar, gastando para ello su hacienda, mientras que don Antonio y los otros dueños de dehesas pretendían disminuirlo. Con este discurso se dejaba claro que los aldeanos eran los mayores defensores del realengo, lo que significaba que sus intereses se identificaban con los de la monarquía, una asociación de ideas que buscaba conferir más fuerza a la reclamación de los campesinos ${ }^{51}$.

49 Ibidem. En la mayoría de los estudios sobre usurpaciones de tierras se ha constatado que los autores de esa práctica solían tener poder político y económico e influencia social, hecho que dificultó la acción de la justicia. Ver, por ejemplo, Diago Hernando, «Las ocupaciones», p. 236; Molénat, «Tolède», p. 366; Pino García, José Luis del. «Usurpaciones de bienes realengos en Córdoba durante la segunda mitad del siglo XV». En Córdoba de la Llave, Ricardo; Pino García, José Luis del y Cabrera Sánchez, Margarita (coords.). Estudios en homenaje al profesor Emilio Cabrera. Córdoba: Universidad de Córdoba, 2015, p. 435; y LuCHÍA, «Poderes locales», p. 230, trabajo este último en el que se alude a la existencia de relaciones de los usurpadores con funcionarios regios.

50 A. G. S., C. C. P., leg. 15, s. f. La información se encuentra en dos documentos diferentes, pero el legajo, como se indica, está sin foliar.

51 La construcción de un discurso en el que se identificaban los intereses de los aldeanos con los de la monarquía ha sido señalada, entre otros, por Luchía, «Poderes locales», p. 221 y «Los aldeanos y la tierra», p. 220. Pero tal discurso se correspondía en buena medida con la realidad, puesto que, en palabras de J. M. a Monsalvo, «los pecheros fueron los mayores defensores del patrimonio comunal tradicional de los concejos» («Percepciones de los pecheros medievales sobre usurpaciones de términos rurales y aprovechamientos comunitarios en los concejos salmantinos y abulenses». Edad Media. Revista de Historia, 2005-2006, vol. 7, p. 44). 
USURPACIONES DE TIERRAS COMUNALES EN EL TÉRMINO DE PLASENCIA

A FINES DE LA EDAD MEDIA

M. ${ }^{\mathrm{a}}$ DOLORES GARCÍA OLIVA

Cabe destacar que estas últimas veces fueron los sexmeros de la tierra quienes denunciaron las usurpaciones, y que fue el concejo de Serradilla quien se opuso a que el corregidor resolviera lo relativo a don Antonio de Monroy. En otras ocasiones también habían sido los aldeanos, no el procurador de la ciudad, los que tomaron la iniciativa, observándose cierta diferencia en el planteamiento de cada uno de ellos. El representante de los aldeanos atribuyó las usurpaciones, en 1490, a «algunos caualleros e otras personas de la dicha çibdad e su tierra, e de sus comarcas, que tienen heredades e dehesas en los términos de la dicha çibdad"; sin embargo, unos meses después el procurador de la ciudad acusó a los señores de Belvís, Talaván, Serrejón, Valverde, Jarandilla y Pasarón de tener ocupados y adehesados muchos términos de la ciudad y de no respetar las sentencias dadas a favor de Plasencia ${ }^{52}$. Es decir, mientras que los concejos de la tierra incluían a caballeros de la ciudad entre los presuntos culpables de las apropiaciones ilegales, el representante concejil centraba el punto de atención en los titulares de señorío, una práctica que detectamos también años después. Recordemos que, en 1504, Alonso de Cáceres, procurador del concejo, solicitó que el corregidor investigara qué tierras estaban ocupadas por caballeros y señores comarcanos, pero en el interrogatorio propuesto por el mismo Alonso de Cáceres dos ańos después para realizar las pesquisas figuraban como inculpados los titulares de seńoríos enclavados en el alfoz placentino y sus villas y el señor de Candeleda. Esta diferencia de planteamiento refleja cómo, ante la presión ejercida por los pecheros para la recuperación de los comunales, el procurador de la ciudad centraba el foco de atención en los señoríos del término, pretendiendo así que la investigación no afectara a los caballeros y otros grandes propietarios de tierras desprovistos de señorío. En muchos casos eran los hombres dependientes del señorío quienes realizaban las apropiaciones, pero ello deparaba el aumento de la base económica y del poder de su señor, por lo que la presentación de las reclamaciones dirigidas contra los señores y sus villas pone de manifiesto, asimismo, la competitividad existente entre los miembros del grupo social hegemónico. $\mathrm{Al}$ respecto, conviene tener en cuenta que este último no formaba un bloque monolítico integrado por personas con el mismo nivel de riqueza, poder e influencia y que compartiera siempre idéntica forma de actuación, puesto que existían fisuras debido a rivalidades personales, problemas familiares o a la confluencia de intereses ${ }^{53}$.

Señores y caballeros, como en muchos otros lugares del reino castellano, fueron los autores principales de las apropiaciones, pero también hemos visto que participaron los campesinos. En el caso de los hombres dependientes de la jurisdicción señorial, los autores materiales de las usurpaciones contaron con el apoyo de sus señores, cuando no también con su estímulo dado que las tierras ocupadas con frecuencia eran incorporadas al término respectivo ${ }^{54}$. De hecho, las acusaciones suelen referirse a las villas y a sus señores conjuntamente, y por ello no siempre es posible delimitar las acciones de unos y de otros.

52 A. G. S., R. G. S., $1490.11,117$ y $1491.06,110$.

53 Monsalvo Antón, «Usurpaciones», pp. i i3-i i4; Luchía, «Poderes locales», p. 228; Pascua ECHEgaray, «Las otras comunidades», pp. 228-229.

54 Diago Hernando, "Las ocupaciones de términos", p. 232; Jara Fuente, "Que memoria de onbre», p. 80; LuchÍA, «Los aldeanos», p. 214 y «Propiedad comunal», p. 286. 
No he encontrado imputaciones de carácter general dirigidas contra los hombres del común del realengo, y las denuncias concretas contra algunos de ellos son excepcionales. Esta exigüidad documental quizá no sea un fiel reflejo de la realidad, ya que, como se ha detectado en otros lugares, los campesinos también participaron en las apropiaciones de tierras, pero estas acciones tuvieron un alcance bastante más limitado ${ }^{55}$. Por ello quizá el mayor número de usurpaciones se localiza en zonas próximas a los señoríos, según se puede observar en el mapa adjunto al final del texto. Entre ellas destacan el área de la Campana de Albalá, situada entre los señoríos de Serrejón, Jaraicejo y los dominios del señor de Belvís, Almaraz y Deleitosa; también afectaron en buena medida a algunas zonas del Campo Arańuelo y al área occidental del realengo comprendida entre el Tajo y el Almonte. En estas zonas la repoblación fue más tardía que en el norte del término placentino, por lo que es presumible que en ellas el proceso de disminución de los comunales se hubiera retrasado en consonancia con la demora detectada en el avance de la ocupación permanente del espacio; quizá por ello a las puertas de los Tiempos Modernos aún ofrecían más posibilidades para proyectar la expansión de los señoríos y de las dehesas de propiedad particular a costa de los baldíos de la tierra placentina.

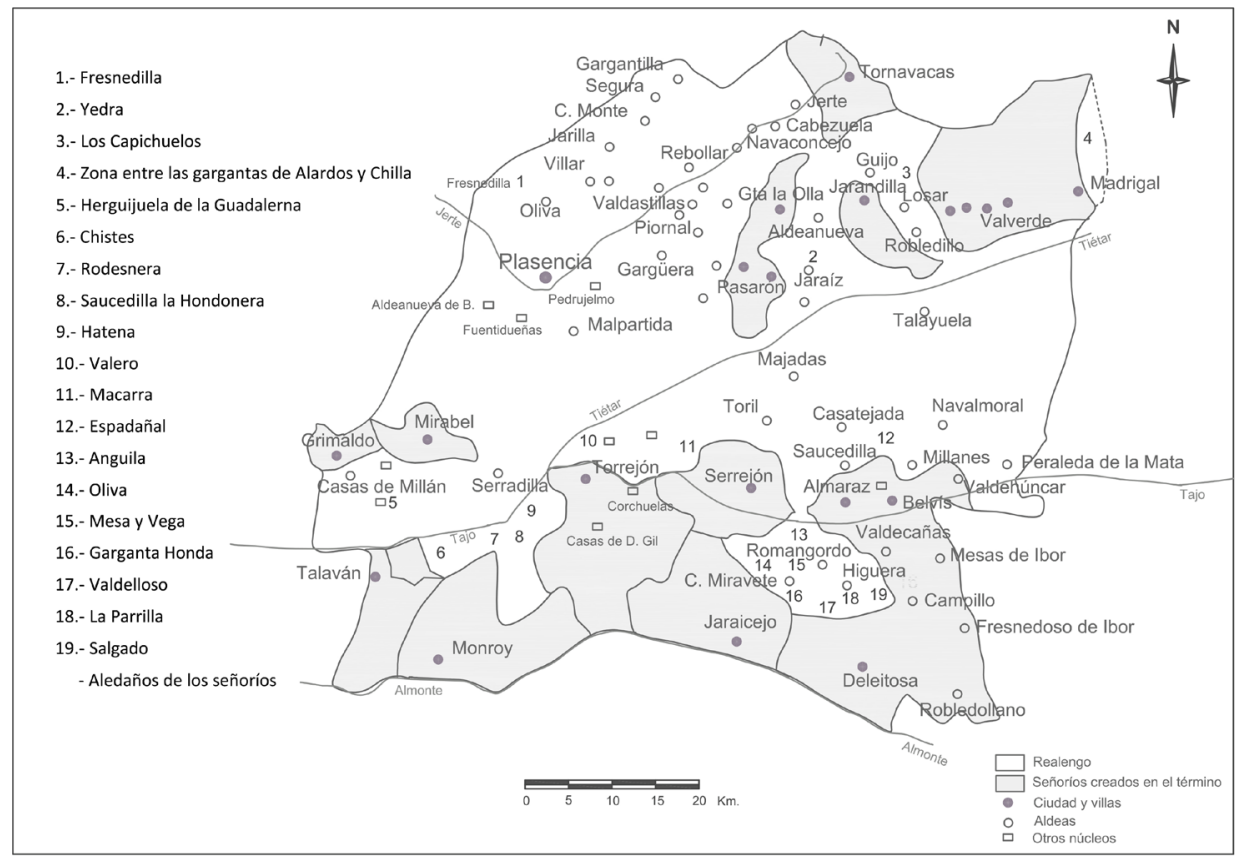

Mapa 1. Tierras usurpadas en el término de Plasencia hacia finales de la Edad Media.

55 Monsalvo Antón, «Usurpaciones», p. 100; Luchía, «Los pleitos», p. 276; y Pino García, «Usurpaciones», p. 435. 
USURPACIONES DE TIERRAS COMUNALES EN EL TÉRMINO DE PLASENCIA

A FINES DE LA EDAD MEDIA

M. ${ }^{\mathrm{a}}$ DOLORES GARCÍA OLIVA

Bernal Estévez, Ángel. Poblamiento, transformación y organización social del espacio extremeño (siglos XIII al XV). Mérida: Editora Regional de Extremadura, 1998.

Cabrera Muñoz, Emilio. «Usurpación de tierras y abusos señoriales en la Sierra cordobesa durante los siglos XIV-XV». Actas del I Congreso de Historia de Andalucía. Andalucía Medieval. Córdoba: Monte de Piedad y Caja de Ahorros de Córdoba, 1978, vol. II, pp. 33-83.

Carmona Ruiz, M. a Antonia. Usurpaciones de tierras y derechos comunales en Sevilla y su "tierra» durante el siglo XV. Madrid: Ministerio de Agricultura, Alimentación y Medio Ambiente, 1995.

Clemente Ramos, Julián. «La explotación económica del Campo Arañuelo y la economía rural de la tierra de Plasencia a mediados del siglo Xv». Anuario de Estudios Medievales, 2009, vol. 39, n. ${ }^{\circ} 1$, pp. 245-274.

Clemente Ramos, Julián. «La tierra de Galisteo (c. 1375-c. 1425). Transformaciones del poblamiento y apropiaciones ilegales». Arqueología y Territorio Medieval, 2010, vol. 17, pp. 31-46.

Cortes de los antiguos reinos de León y de Castilla. Madrid: Sucesores de Rivadeneyra, 1882, t. IV.

Diago Hernando, Máximo. "Las ocupaciones de términos en la tierra de Cuenca a fines de la Edad Media: algunas peculiaridades locales de una práctica generalizada en la Corona de Castilla». En Val Valdivieso, María Isabel y Martínez Sopena, Pascual (eds.). Castilla y el mundo feudal: homenaje al profesor Julio Valdeón. Vol. 3. Valladolid: Universidad de Valladolid, 2009, pp. 229-240.

Franco Silva, Alfonso y Pino García, José Luis del. «El señorío de Monroy (siglos XiII-Xv)». En Hernán Cortés y su tiempo. Mérida: Editora Regional de Extremadura, 1987, vol. 1, pp. 153-165.

García Oliva, M. ${ }^{a}$ Dolores. Poblamiento y expansión de las dehesas en el realengo de Extremadura, siglos XIII-XV. Cáceres: Universidad de Extremadura, 2015.

Gerbet, Marie-Claude. La noblesse dans le royaume de Castille. Étude sur ses structures sociales en Estrémadure de 1454 à 1516. Paris: Publications de la Sorbonne, 1979.

Jara Fuente, José Antonio. "Que memoria de onbre non es en contrario. Usurpación de tierras y manipulación del pasado en la Castilla urbana del siglo Xv». Studia Historica. Historia Medieval, 2002-2003, vol. 20-21, pp. 73-103.

Lorenzo Pinar, Francisco Javier, e IzQuierdo Misiego, José Ignacio, «Términos redondos y despoblamiento en Ávila al inicio de la Edad Moderna. Aproximación histórica». Studia Zamorensia. Segunda Etapa, 2002, vol. 6, pp. 255-270.

Luchía, Corina. "Los aldeanos y la tierra: percepciones campesinas en los concejos castellanos, siglos XIV-XvI». Studia Historica. Historia Medieval, 2011, vol. 29, pp. 207-228.

Luchía, Corina. «Los pleitos por los términos comunales en el concejo de Ciudad Rodrigo en la Baja Edad Media». Historia. Instituciones. Documentos, 2008, vol. 35, pp. 269-290.

Luchía, Corina. «Poderes locales, monarquía y propiedad comunal en los concejos de realengo castellanos bajomedievales». Anales de la Universidad de Alicante. Historia Medieval, 20062008, vol. 15, pp. 215-238.

Luchía, Corina. «Propiedad comunal y lucha de clases en la Baja Edad Media castellano-leonesa. Una aproximación a la dialéctica de la propiedad comunal». Anales de Historia Antigua, Medieval y Moderna, 2003, vol. 35-36, pp. 235-268.

Luis López, Carmelo. "Las comarcas meridionales de la tierra abulense medieval: precisiones a una problemática delimitación y repoblación». Studia Historica. Historia Medieval, 20022003, vol. 20-21, pp. 11-45. 
USURPACIONES DE TIERRAS COMUNALES EN EL TÉRMINO DE PLASENCIA

A FINES DE LA EDAD MEDIA

178

M. ${ }^{\mathrm{a}}$ DOLORES GARCÍA OLIVA

Martín Martín, José Luis. "Evolución de los bienes comunales en el siglo xv». Studia Historica. Historia Medieval, 1990, vol. 8, pp. 7-46.

MolÉnAT, Jean-Pierre. «Tolède et ses finages au temps des Rois Catholiques. Contribution à l'historie sociale et économique de la cité avant la révolte des Comunidades». Mélanges de la Casa de Velázquez, 1972, vol. 8, pp. 327-377.

Monsalvo Antón, José M. ${ }^{a}$. «Paisaje agrario, régimen de aprovechamientos y cambio de propiedad en una aldea de la tierra de Ávila durante el siglo Xv. La creación del término redondo de Zapardiel de Serrezuela». Cuadernos Abulenses, 1992, vol. 17, pp. 11-110.

Monsalvo Antón, José M. ${ }^{a}$. "Percepciones de los pecheros medievales sobre usurpaciones de términos rurales y aprovechamientos comunitarios en los concejos salmantinos y abulenses». Edad Media. Revista de Historia, 2005-2006, vol. 7, p. 37-74.

Monsalvo Antón, José M. ${ }^{a}$. "Usurpaciones de comunales: conflicto social y disputa legal en Ávila y su Tierra durante la Baja Edad Media». Historia Agraria, 2001, vol. 24, p. 89-122.

Montaña Conchiña, Juan Luis de la. «Señorialización y usurpaciones terminiegas de espacios realengos: El caso de Badajoz en los siglos XIV-XV». Norba. Revista de Historia, 1996-2003, vol. 16 , n. ${ }^{\circ} 1$, pp. 345-360.

Oliva Herrer, Hipólito Rafael. "Conflictos antiseńoriales en el reino de Castilla a fines de la Edad Media: viejas preguntas, ¿nuevas respuestas?». Historia. Instituciones. Documentos, 2009, vol. 36, pp. 313-331.

Oliva Herrer, Hipólito Rafael. Justicia contra señores. El mundo rural y la política en tiempos de los Reyes Católicos. Valladolid: Universidad de Valladolid, 2004.

Pascua Echegaray, Esther. «Las otras comunidades: pastores y ganaderos en la Castilla medieval». En Rodríguez, Ana (coord.). El lugar del campesino. En torno a la obra de Reyna Pastor. València: Consejo Superior de Investigaciones Científicas-Universitat de València, 2007, pp. 209-238.

Pino García, José Luis del. «Pleitos y usurpaciones de tierras realengas en Córdoba a fines del siglo Xv: la Villa de las Posadas». Estudios de Historia de España, 2010, vol. 12, n. ${ }^{\circ} 1$, pp. 117-160.

Pino García, José Luis del. «Usurpaciones de bienes realengos en Córdoba durante la segunda mitad del siglo XV». En Córdoba de la Llave, Ricardo; Pino García, José Luis del y Cabrera Sánchez, Margarita (coords.). Estudios en homenaje al profesor Emilio Cabrera. Córdoba: Universidad de Córdoba, 2015, pp. 431-466.

Plaza de Agustín, Javier. «La usurpación de tierras comunales y baldíos en Guadalajara durante la segunda mitad del siglo Xv». Espacio, Tiempo y Forma. Serie III, Historia Medieval, 2015, vol. 28, pp. 459-485.

Rodríguez Amaya, Esteban. «La tierra en Badajoz desde 1230 a 1500». Revista de Estudios Extremeños, 1951, vol. VII, pp. 395-497.

Sánchez Loro, Domingo. Historias placentinas inéditas. Primera parte, Catalogus ecclesiae placentinae. Vol. A. Cáceres: Institución Cultural El Brocense, 1982.

Sánchez Loro, Domingo. Historias placentinas inéditas. Primera parte, Catalogus ecclesiae placentinae. Vol. C. Cáceres: Institución Cultural El Brocense, 1985.

Santos Canalejo, Elisa Carolina de. El siglo XV en Plasencia y su tierra. Cáceres: Institución Cultural El Brocense, 1981. 